\title{
Trends and causes of maternal mortality in a tertiary care hospital over five years: 2013-2017
}

\author{
Sonia Rafiq ${ }^{1}$, Wajeeha Syed ${ }^{2}$, Simi Fayaz Ghaffar ${ }^{3}$
}

\begin{abstract}
Background and Objective: Maternal death measurement is essential to a country's wellbeing and development status. In emerging countries like Pakistan, it remains an intimidating and failed public health challenge. Objectives of our audit were to estimate trends and causes of maternal demise in Lady Reading Hospital, Peshawar, Pakistan.

Methods: Between January 2013 to December 2017, a retrospective study was carried out at Medical Teaching Institute, Lady Reading Hospital, Peshawar. A structured proforma was used to collect data from the medical records. To detect trends in mother demise maternal mortality ratio was calculated for each year and for all five years, Spss version 23 was used for data analysis.

Results: In the five-year periods 134 deaths were recorded. The maternal mortality during the study period was 431/100,000 live births. An unstable trend in mortality with two crowning periods in 2013 and 2017 was observed. Hemorrhage persisted as the foremost cause of maternal death over the five years period, accounting for $47.76 \%$ deaths followed by hypertension, accounting for $25.37 \%$ deaths. An increased risk of $35.08 \%$ was observed among women aged $25-29$ years, followed by $26.11 \%$ in $20-24$ years and $23.88 \%$ in $>30$ years.

Conclusion: There is a decreasing trend of maternal death from 2013 to 2016 but a slight increase was noted in 2017. Hemorrhage was the top cause responsible for the maternal death.
\end{abstract}

KEYWORDS: Maternal mortality, Maternal mortality rate, Hemorrhage, Hypertension.

doi: https://doi.org/10.12669/pjms.35.4.1091

How to cite this:

Rafiq S, Syed W, Ghaffar SF. Trends and causes of maternal mortality in a tertiary care hospital over five years: 2013-2017. Pak J Med Sci. 2019;35(4):1128-1131. doi: https://doi.org/10.12669/pjms.35.4.1091

This is an Open Access article distributed under the terms of the Creative Commons Attribution License (http://creativecommons.org/licenses/by/3.0), which permits unrestricted use, distribution, and reproduction in any medium, provided the original work is properly cited.

\section{INTRODUCTION}

1. Dr. Sonia Rafiq, FCPS.

2. Dr. Wajeeha Syed, FCPS.

3. Dr. Simi Fayaz Ghaffar, FRCOG, FCPS.

1-3: Department of Obstetrics \& Gynaecology, Lady Reading Hospital,

Peshawar, Pakistan.

Correspondence:

Dr. Wajeeha Syed, Assistant Professor, Gyne C unit, Lady Reading Hospital,

Peshawar, Pakistan.

Email: mohammadabbas1979@hotmail.com

* Receive for Publication:

* $1^{\text {st }}$ Revision Received:

* $2^{\text {nd }}$ Revision Received:

* Final Revision Accepted:
September 18, 2018

November 20, 2018

May 20, 2019

May 23, 2019
Maternal mortality is defined by World health organization ( $\mathrm{WHO}$ ) as the demise of a woman during maternity in the first 42 days of cessation of pregnancy, regardless of site \& time of the pregnancy, from any reason linked to gravidity or its management, but not from unintentional causes. In the emerging countries like Pakistan maternal health has become one of the main public health worries after the first safe motherhood meeting held in Kenya in 1987. ${ }^{1}$ Still, maternal mortality is at the top of a global challenge with more than 0.3 million deaths take place due to pregnancy and its complication in the year 2015. A target was set by the millennium development goal to reduce MMR by $75 \%$ in the year $2015 .{ }^{2}$ During the year 2013 MMR in developed and developing countries was 
$16 / 100,000$ and 230/100,00 live births respectively in which chief input of the global maternal deaths was from African region alone (62\%) followed by Southern Asia (24\%). ${ }^{3}$

In 2013 MMR has declined in Pakistan from 400 in 1990 to 230 in 2013, currently, Pakistan is off-track and lags behind the target (140) set for 2015. ${ }^{4}$ Numerous native studies have shown mutable figures for MMR from dissimilar parts of the study. ${ }^{5,6}$ Haemorrhage is the leading cause of maternal deaths. ${ }^{7}$ Poverty, Meagre access to healthcare facilities, lack of skilled primary health care providers and local custom and fondness of home deliveries are contributing towards higher mortalities in Pakistan. ${ }^{8}$

Our study was commenced to find the trends in the maternal mortality in our hospital and to determine the major causes of death and to ascertain if there are any significant deviations from other reports.

\section{METHODS}

This retrospective study of maternal deaths was carried out from January 2013 to December 2017 at Medical Teaching Institute, Lady Reading Hospital, Peshawar, Pakistan. Data collection tool was a selfstructured proforma, on which required data was collected from the medical records the medical records of maternal deaths were studied. Data on all the cases was haul out from the Labour unit register, patient's case notes and maternal mortality records. From the delivery register demographic data, total deliveries and live birth for the period were noted.

Only those females were counted in who acceded to death during and after delivery, rest all morbidity cases were excluded from the study. The patients who reach hospital in emergency condition or dead while reaching were excluded. Consent was taken from Medical Superintendent of the hospital and Head of Department of Gynaecology/ Obstetrics ward, Leady Reading Hospital, Peshawar. Privacy was ensured regarding the collected data that it was chastely for research purposes and will not be public with the third party. The Ethical Review Board of Lady Reading Hospital, Pakistan approved the study.

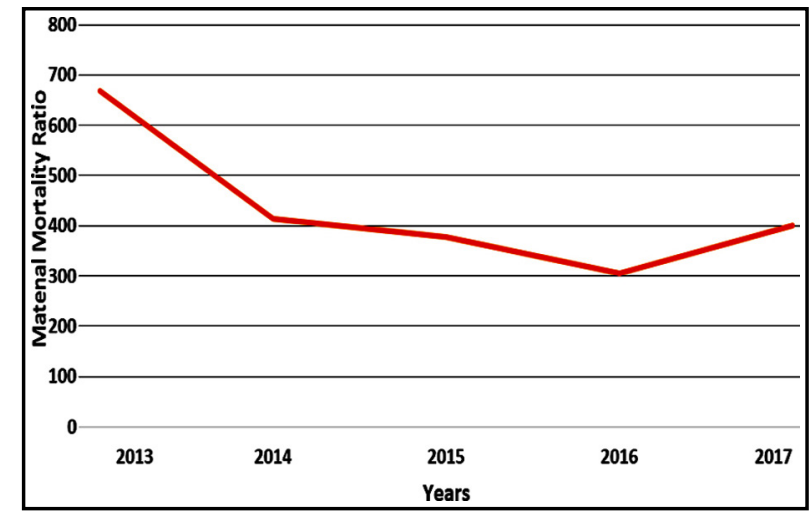

Fig.1: Trends in maternal mortality over five years.

Statistical analysis was achieved by using the Statistical Package for Social Science (SPSS) version 23. Continuous data were showed as the mean \pm standard deviation, while the categorical and nominal data were presented as frequencies and percentages.

\section{RESULTS}

A total of 134 deaths were logged in five years study period. The MMR during the study period was 431/100,000 live births as shown in Table-I. A changing trend in MMR with two peak periods in 2013 and 2017 was detected as shown in Fig.1. Hemorrhage remained the principal cause of maternal mortality over the five years period, accounting for $64(47.76 \%)$ deaths followed by hypertension accounting $34(25.37 \%)$ deaths. Sepsis leads to $06(4.47 \%)$ maternal deaths. Table-II shows all the direct and indirect causes of maternal mortality. An increased risk of $35.08 \%$ was observed among women aged 25-29 years, followed by $26.11 \%$ ) in $20-24$ years and $23.88 \%$ in $>30$ years, depicted in Table-III.

\section{DISCUSSION}

In our study, the annual maternal mortality ratio of $431 / 100,000$ was observed over the period of five years. It was quite lower as compared to another part of the country. Studies from Punjab and Sindh have found MMRs in the range of $1017-2736 / 100,000$ live births. ${ }^{9-12}$ South Asian developing countries

Table-I: Trends in maternal mortality: 2013-2017.

\begin{tabular}{lcccccc}
\hline & 2013 & 2014 & 2015 & 2016 & 2017 & Total \\
\hline Total birth & 7435 & 6400 & 7892 & 7684 & 7847 & 37,258 \\
Live birth & 6124 & 5550 & 5560 & 6864 & 6984 & 31,082 \\
$\begin{array}{l}\text { Maternal death } \\
\begin{array}{l}\text { Maternal } \\
\text { mortality ratio (MMR) }\end{array}\end{array}$ & 61 & 23 & 21 & 21 & 28 & 134 \\
\hline
\end{tabular}


Trends and causes of maternal mortality

Table-II: Demographic characteristics of maternal deaths.

\begin{tabular}{|c|c|c|c|c|c|c|}
\hline & $\begin{array}{c}2013 \\
(n=41)\end{array}$ & $\begin{array}{c}2014 \\
(n=23)\end{array}$ & $\begin{array}{c}2015 \\
(n=21)\end{array}$ & $\begin{array}{c}2016 \\
(n=21)\end{array}$ & $\begin{array}{c}2017 \\
(n=28)\end{array}$ & $\begin{array}{c}\text { Total } \\
(n=134)\end{array}$ \\
\hline \multicolumn{7}{|l|}{ Age } \\
\hline$<20$ years & $06(14.63 \%)$ & 03(13.04\%) & $03(14.28 \%)$ & $04(19.04 \%)$ & $04(14.28 \%)$ & $20(14.92 \%)$ \\
\hline 20-24 years & $10(24.39 \%)$ & $05(21.73 \%)$ & $07(33.33 \%)$ & $06(28.57 \%)$ & $07(25 \%)$ & $35(26.11 \%)$ \\
\hline $25-29$ years & $15(36.58 \%)$ & $09(39.13 \%)$ & $07(33.33 \%)$ & $07(33.33 \%)$ & $09(32.14 \%)$ & $47(35.08 \%)$ \\
\hline$>30$ years & $10(24.39 \%)$ & $06((26.08 \%)$ & $04((19.04 \%)$ & $04(19.04 \%)$ & $08(28.57 \%)$ & $32(23.88 \%)$ \\
\hline \multicolumn{7}{|l|}{ Parity } \\
\hline Primigravida & $09(21.95 \%)$ & $04(17.39 \%)$ & $06(28.57 \%)$ & $05(23.80 \%)$ & $05(17.85 \%)$ & $29(21.64 \%)$ \\
\hline Multigravida & $17(41.46 \%)$ & $11(47.82 \%)$ & $09(42.85 \%)$ & $11(52.38 \%)$ & $13(46.42 \%)$ & $61(45.52 \%)$ \\
\hline \multicolumn{7}{|l|}{ Antenatal Care } \\
\hline Yes & $09(21.95 \%)$ & $07(30.43 \%)$ & $06(28.57 \%)$ & $04(19.04 \%)$ & $06(21.42 \%)$ & $32(23.88 \%)$ \\
\hline No & $32(78.04 \%)$ & $16(69.56 \%)$ & $15(71.42 \%)$ & $17(80.95 \%)$ & $22(28.57 \%)$ & $102(76.11 \%)$ \\
\hline
\end{tabular}

Table-III: Causes of maternal mortality: 2013-2017.

\begin{tabular}{lcccccc}
\hline Causes of MMR & $\begin{array}{c}2013 \\
(n=41)\end{array}$ & $\begin{array}{c}2014 \\
(n=23)\end{array}$ & $\begin{array}{c}2015 \\
(n=21)\end{array}$ & $\begin{array}{c}2016 \\
(n=21)\end{array}$ & $\begin{array}{c}2017 \\
(n=28)\end{array}$ & $\begin{array}{c}\text { Total } \\
(n=134)\end{array}$ \\
\hline Hemorrhage & $21(51.21 \%)$ & $12(52.17 \%)$ & $07(33.33 \%)$ & $10(47.61 \%)$ & $14(50 \%)$ & $64(47.76 \%)$ \\
Hypertensive & $11(26.82 \%)$ & $06(26.08 \%)$ & $0733.33 \%)$ & $08(38.09 \%)$ & $02(7.14 \%)$ & $34(25.37 \%)$ \\
Thromboembolism & $03(7.31 \%)$ & $02(8.69 \%)$ & $02(9.52 \%)$ & $02(9.52 \%)$ & $01(3.57 \%)$ & $10(7.46 \%)$ \\
Sepsis & $01(2.43 \%)$ & $01(4.34 \%)$ & 00 & 00 & $04(14.28 \%$ & $06(4.47 \%)$ \\
Anaesthesia complication & 00 & 00 & 00 & 00 & $01(3.57 \%)$ & $01(0.74 \%)$ \\
Cardiomyopathy & $02(4.87 \%)$ & 00 & $2(9.52 \%)$ & $01(4.76 \%)$ & $01(3.57 \%)$ & $06(4.47 \%)$ \\
Status epilepticus & $01(2.43 \%)$ & 00 & 00 & 00 & 00 & $01(0.74 \%)$ \\
Hepatic failure & $02(4.87 \%)$ & $02(8.69 \%)$ & $3(14.28 \%)$ & 00 & $03(10.71 \%)$ & $10(7.46 \%)$ \\
Obstructive uropathy & 00 & 00 & 00 & 00 & $01(3.57 \%)$ & $01(0.74 \%)$ \\
Thyrotoxicosis & 00 & 00 & 00 & 00 & $01(3.57 \%)$ & $01(0.74 \%)$ \\
\hline
\end{tabular}

like India, Pakistan, and Bangladesh have a chief share of maternal deaths throughout the world. ${ }^{13}$ In the yearly trends, maternal deaths fall significantly, from the year 2013 to 2016. However significant cause was found for this positive change.

Women in countryside do not obtain antenatal care and most of the birth take place at home which is attended by inexpert personnel. As observed, non-utilization of antenatal clinic contributes to maternal mortality. Maternal death is on the higher side in antenatal cases $76.11 \%$ because of absence of awareness regarding antenatal care, lack of institutional delivery and low availability to healthcare facility. Earlier research has shown that a noteworthy proportion of maternal death and lifethreatening complications occurred in those who did not receive antenatal care but referred to the maternity unit in an emergency condition. ${ }^{14}$

Hemorrhage was steadily observed to be the foremost cause of demise in all five years. Over all, it accounted for $47.76 \%$ of deaths. It is not a leading contributor in the developing country but also accounts for significant death in developed coun- tries. ${ }^{15,16}$ Khan et al. ${ }^{17}$ observe that hemorrhages, infection, organ dysfunction and anemia were among the chief causes of maternal mortality in their studies. In the same study, the authors found mortality were high in cases where delivery was not planned prenatally. In studies from India by Priya et al hemorrhage was the leading cause of maternal mortality of $35.05 \% .^{18}$ Though the number of maternal deaths due to hemorrhages has declined because of increased hospital delivery and antenatal care, still it accounts for the maximum maternal deaths. Maternal deaths due to anemia have also decreased due to proper health care facility and nutrition.

Second leading cause of death was hypertension which accounts for $25.37 \%$ deaths. In Latin America, hypertensive disorders during pregnancy $(25.7 \%)$ were the commonest cause of death. In advanced countries, most deaths are due to mainly complication of anesthesia and surgery. ${ }^{19}$ Hypertensive illnesses of pregnancy were the major cause of maternal mortality in studies by Singh et al and Paul et al being $24.01 \%$ and $32.6 \%$ respectively. ${ }^{20,21}$ 
Pregnancy rises hypercoagulability, stasis, and idleness increase coagulation susceptibility. Among the causes of death of the cases, thromboembolism was the $3 \mathrm{rd}$ most frequent cause detected in all cases. thromboembolism is one of the life-threatening causes in pregnant women. Approximately $15 \%$ of maternal deaths in developed countries are due to thromboembolism.

Almost $35 \%$ of deaths were in the age group between 25-30 years. Our country teenage marriages are common and high fertility rates, high levels of poverty and illiteracy as well as gender discrimination have compounded the situation. In fact, a poor woman is many times more likely to die during childbirth due to malnutrition and anemia. ${ }^{22}$ The lifetime risk of a woman dying due to pregnancy-related causes in developing countries is 1:40 as compared to 1:3600 in the developed world. ${ }^{23}$

\section{CONCLUSION}

There is a decreasing trend of maternal death from 2013 to 2016 but a slight increase was noted in 2017. The maternal mortality ratios remain high. Hemorrhage obstinately contributed as the major causative factor. The findings of the study highlight the need for comprehensive efforts using multisectoral collaborations from stakeholders in reducing maternal mortality.

\section{Grant Support \& Financial disclosure: None.}

\section{REFERENCES}

1. Mahler H. The safe motherhood initiative: a call to action. Lancet. 1987;1(8534):668-670. doi: 10.1016/S01406736(87)90423-5

2. United Nations. The Millennium Development Goals Report 2015. New York: United Nations; 2015.

3. Trends in Maternal Mortality: 1990 to 2013. Estimates by WHO, UNICEF, UNFPA, The World Bank and the United Nations Population Division. [Cited on December 28, 2014]. Available from URL: http://apps.who.int/iris/ bitstream/10665/112682/2/9789241507226_eng.pdf

4. Ministry of Planning, Development and Reform. Government of Pakistan. Pakistan Millennium Development Goals Report 2013. [Cited on October 20, 2014]. Available from URL: http://www.undp.org/ content/dam/pakistan/docs/MDGs/MDG2013Report/ UNDP-Report13.pdf

5. Khan SM, Saleem M, Razzaq A. Incidence of near-miss maternal mortality in the department of obstetrics \& gynaecology Sh. Zayed Medical College / Hospital, Rahim Yar Khan. Pak J Med Health Sci. 2010;4(1):44-45.

6. Fahim F, Nabeel N, Utman N. Trends in Maternal Mortality in tertiary care hospital in Peshawar - Pakistan. J Postgrad Med Inst. 2012;26(4):422-427.

7. PDHS, National Institute of Population Studies \& Demographic and Health Surveys. Pakistan Demographic and Health Survey. 2006-2007.
8. Butt MA. Women's Health Problems in Pakistan. Middle East J Fam Med. 2004;2 (2):1-17.

9. Jafarey SN, Maternal mortality in Pakistan: compilation of available data. J Pak Med Assoc 2002;52:539-544.

10. Begum S, Aziz-un-Nisa, Begum I. Analysis of maternal mortality in a tertiary care hospital to determine causes and preventable factors. J Ayub Med Coll Abbottabad. 2003;15:49-52.

11. Bano B, Chaudhri R, Yasmeen L, Shafi F, Ejaz L. A study of maternal mortality in 8 principal hospitals in Pakistan in 2009. Int J Gynaecol Obstet. 2011;114:255-259. doi: 10.1016/j. ijgo.2011.03.018

12. Qureshi RN, Jaleel S, Hamid R, Lakha SF. Maternal deaths in a developing country: A study from Agha Khan University Hospital, Karachi, 1988-1999. J Pak Med Assoc. 2001;51:109-111.

13. Naney L, Sloan A, Langer B, Hernanez M, Romero B. The etiology of maternal mortality in developing countries: What do verbal autopsies tell us? Bull World Health Organ. 2001;79:46-49.

14. Agan T, Archibong E, Ekabua J, Ekanem E, Abeshi S, Edentekhe $\mathrm{T}$, et al. Trends in maternal mortality at the University of Calabar Teaching Hospital, Nigeria, 19992009. Int J Women's Health. 2010;2:249.

15. Liang J, Pai L, Zhu J, Li X, Zeng W, Wang H, et al. Preventable maternal mortality: et al. Preventable maternal mortality: associated factors from the population - based maternal mortality surveillance system in China. BMC Public Health. 2011;11:243. doi: 10.1186/1471-2458-11-243.

16. Wildman K, Bouvier-Colle MH, MOMS Group. Maternal mortality as an indicator of obstetric care in Europe. BJOG. 2004;111:164- 169. doi: 10.1046/j.1471-0528.2003.00034.x-i1

17. Khan T, Laul P, Laul A, Ramzan M. Prognostic factors of maternal near miss events and maternal deaths in a tertiary healthcare facility in India. Int J Gynaecol Obstet. 2017;138:171-176.

18. Priya N, Verma A, Verma S. Maternal mortality: Ten years retrospective study. J Med Educ Res. 2010;12:134-136.

19. Purandre N, Chandock A, Upadhya S, Sanjanwala SM. Maternal mortality at a referral centre: A five year study. J Obstet Gynecol India. 2007:57:248-250.

20. Singh R, Sinha N, Bhattacharyya K, Ram R. Pattern of maternal mortality in a tertiary care hospital of patna, Bihar. Indian J Community Med. 2009;34:73-74. doi: 10.4103/09700218.45381

21. Paul B, Mohpatra B, Kar K. Maternal Deaths in a Tertiary Care Centre of Odisha: An In-depth study Supplemented by Verbal Autopsy. Indian J Community Med. 2011;36:213-216. doi: 10.4103/0970-0218.86523

22. Maternal Mortality in 2000. Estimates developed by WHO, UNICEF and UNFPA, Geneva, Switzerland, WHO; 2004.

23. Farooq N, Jadoon H, Masood T, Wazir MS, Farooq U, Lodhi MS. An assessment study of maternal mortality ratio data bank in five districts of North Western Frontier Province Pakistan. J Ayub Med Coll Abbottabad. 2006;18:64-68.

\section{Authors' Contribution:}

SR: Conceived the idea, did data collection \& manuscript writing.

WS: Did statistical analysis \& editing of manuscript. SFG: Did review \& final approval of manuscript. 